\title{
Effects of 16-week spinning and bicycle exercise on body composition, physical fitness and blood variables of middle school students
}

\author{
Jang-Gun Yoon', Seok-Hee Kim², Hyun-Seung Rhyu ${ }^{3, *}$ \\ 'Department of Special Forces Medical Non-commissioned, Daejeon Health Institute of Technology, Daejeon, Korea \\ ${ }^{2}$ School of Humanities and Social Sciences, Korea Advanced Institute of Science and Technology, Daejeon, Korea \\ ${ }^{3}$ Department of Sports Health Medicine, Jungwon University, Goesan, Korea
}

The purpose of this study was to investigate the effects of 16 weeks of spinning and bicycling exercises on body composition, physical fitness and blood variables in female adolescents. Subjects participated in this study were 24 female middle school students (12 spinning cycles, 12 general bicycles) attending to Seoul Yeoksam middle school. Each group was trained for 16 weeks, 3 times a week, and $1 \mathrm{hr}$ per day after school. Body composition, physical fitness (1,200 running, sit-ups, back strength, sit and reach, side-steps) and blood variables (low-density lipoprotein cholesterol, glucose, reactive oxygen species, and malondialdehyde) were examined before and after 16 weeks of training. As the results, body weight did not show any significant difference; however, body mass index, and \% body fat were significantly difference in spin- ning group. The enhancement in physical fitness factors were recognized in both groups, which was greater in spinning group in sit-ups, back strength, and side steps. Blood parameters were significantly difference between groups, but between group and time interactions were significantly difference in glucose and reactive oxygen species. In conclusion, this study suggests that 16 weeks of bicycle exercises were positive changes in body composition, physical fitness and blood constituents, indicating that spinning cycle is more beneficial as compared to ordinary bicycle.

Keywords: Female middle school students, Spinning cycles, General bicycles, Body composition, Physical fitness, Blood variables

\section{INTRODUCTION}

Physical changes in adolescence begin from the age of 11 to the early 20 years, and sex differences are noticeable with changes in the endocrine system during the middle school period, which results in the rapid growth of secondary development. In addition to the development of the musculoskeletal system, somatic development may occur and, at the same time, differences in growth rates due to physical imbalance may arise (Greydanus and Omar, 2014).

In this period, most youth in Korea have experienced a great reduction in physical activities due to the rapid development of game culture using electronic devices instead of educational policies and physical activities centered on entrance examinations (Lee

et al., 2015).

Regular physical activity plays an important role in improving the quality of life by preventing various diseases related to cardiovascular and pulmonary system and by preventing the incidence of degenerative diseases of the musculoskeletal system (Petersen and Ueda, 2008). In addition, regular exercise is known to reduce mental depression and anxiety and promote self-confidence (American College of Sports Medicine, 2013). In particular, the development of physique and physical fitness in adolescence has been reported to be particularly important since the poor health outcomes at this age may be carried out to adulthood and youthfulness (Cattuzzo et al., 2016). Regular physical activity has been shown to improve memory and learning skills, therefore, it is particularly

${ }^{*}$ Corresponding author: Hyun-Seung Rhyu (iD https://orcid.org/0000-0002-4987-7482 Department of Sports Health Medicine, Jungwon University, 85 Munmu-ro, Goesan-eup, Goesan 28024, Korea

Tel: +82-43-830-8859, Fax: +82-43-830-8589, E-mail: rhyuhs@jwu.ac.kr Received: July 22, 2017 / Accepted: August 10, 2017 
important for school-aged adolescents (Chaddock et al., 2011).

Several studies in Korea have reported that sustained aerobic exercise has positive influence on obesity prevention and physical fitness in adolescents (Lee et al., 2010; Rhyu et al., 2014). Some studies have reported positive effects on body composition and blood lipid as a result of continuous exercise program participation (Lee et al., 2012; Strong et al., 2005).

Bicycling is one of the most popular sporting events in Korea. Many middle and high school students in Korea commute to school by bicycle. Recently, the popularity of spinning cycles is high, but it is an exercise that is carried out indoors rather than outdoors. It is an exercise modality using both upper body and lower body together with music of fast rhythm on a fixed bicycle, and is known as a popular sport especially for women. Especially, spinning is reported as an exercise that consumes twice as much calories as a general bicycle exercise (Battista et al., 2008; Caria et al., 2007; Hazelhurst and Claassen, 2006; Kang et al., 2005; López-Miñarro et al., 2010).

The purpose of this study was to investigate the effect of 16 weeks of spinning or bicycling exercises on body composition, physical fitness and blood variables of female middle school students and to propose an effective exercise mode for prevention of obesity and improvement of physical fitness.

\section{MATERIALS AND METHODS}

\section{Participants}

Twenty-four female middle school students participated in this study. Among them 12 students were randomly assigned to spinning cycle group ( $13.3 \pm 0.42$ years) and the rest 12 students were to general bicycle group (13.4 \pm 0.38 years). Physical characteristics of the subjects are listed in Table 1.

\section{Experimental procedures}

\section{Evaluation of body composition}

The measurement of body composition was processed after arriving in examination place, removing the carried metals, urinated $30 \mathrm{~min}$ before measurement, and taking $5 \mathrm{~min}$ of break in

Table 1. Physical characteristics of the subjects $(n=24)$

\begin{tabular}{lccc}
\hline Group & Age $(\mathrm{yr})$ & Height $(\mathrm{cm})$ & Weight $(\mathrm{kg})$ \\
\hline $\mathrm{SC}(\mathrm{n}=12)$ & $13.3 \pm 0.42$ & $157.00 \pm 3.57$ & $49.38 \pm 3.44$ \\
$\mathrm{~GB}(\mathrm{n}=12)$ & $13.4 \pm 0.38$ & $156.57 \pm 4.59$ & $47.47 \pm 5.74$ \\
\hline
\end{tabular}

Values are presented as mean \pm standard deviation.

$\mathrm{SC}$, spinning cycle; GB, general bicycle. comforting status. Weight, body mass index, and percentage of body fat were assessed using body composition measuring instrument, Inbody 720 (Biospace Co., Seoul, Korea).

\section{Performance-related physical fitness tests}

Performance-related physical fitness was evaluated by conducting tests related to aerobic capacity, muscle strength, muscle endurance, flexibility and Agility. Aerobic capacity was evaluated by measuring the time taken to finish a 1,200-m sprint. Muscle strength was evaluated based on the measurement of back muscle strength (Model 5402, Takei, Niigata, Japan) using a digital measuring instrument, muscle endurance by measuring the number of sit-ups performed in $60 \mathrm{sec}$, flexibility by measuring sit and reach, and agility by measuring side-step test.

\section{Blood analysis}

Blood samples were obtained from all subjects before and after the 16 weeks of exercise training. Blood samples were collected from the antecubital vein using 22-G needles after 30-min rest following body composition evaluation. The collected blood was subjected to analyses of total cholesterol (TC), low-density lipoprotein cholesterol (LDL-C), glucose, reactive oxygen species (ROS), and malondialdehyde (MDA).

\section{Exercise program}

The spinning group and bicycle group participated in exercise program, each group was trained for 16 weeks, 3 times a week, and $1 \mathrm{hr}$ per day after school. Each exercise session consisted of a 10-min warm-up exercise, 40-min spinning or bicycle exercise, and 10-min cool-down exercise. The warm-up and cool-down exercises were comprised of $10 \mathrm{~min}$ of stretching and breathing exercises. The spinning and bicycle exercise were designed with consideration of target heart rate (THR) 45\%-60\%. All exercises were performed with supervision to ensure all exercise motions were performed accurately.

\section{Statistical analysis}

Statistical processing was performed using IBM SPSS Statistics ver. 21.0 (IBM Co., Armonk, NY, USA). It was used to calculate the mean and standard deviation values for data processing in the present study. To determine intergroup mean differences, repeated-measure two-way analysis of variance was conducted to analyze the main and interaction effects. The significance level $(\alpha)$ was set to $P<0.05$. 
Table 2. Changes in body composition

\begin{tabular}{|c|c|c|c|c|c|c|}
\hline \multirow{2}{*}{ Variable } & \multicolumn{2}{|c|}{$S C$ group $(n=12)$} & \multicolumn{2}{|c|}{ GB group $(n=12)$} & \multirow{2}{*}{\multicolumn{2}{|c|}{$F$-value }} \\
\hline & Pre & Post & Pre & Post & & \\
\hline \multirow{3}{*}{ Height (cm) } & $157.00 \pm 3.57$ & $158.70 \pm 3.17$ & $156.57 \pm 4.59$ & $157.72 \pm 4.76$ & $G$ & $67.816^{* * *}$ \\
\hline & & & & & $\mathrm{T}$ & 0.178 \\
\hline & & & & & $G \times T$ & 2.526 \\
\hline \multirow[t]{3}{*}{ Weight (kg) } & $49.38 \pm 3.44$ & $49.21 \pm 3.30$ & $47.47 \pm 5.74$ & $48.89 \pm 5.69$ & G & 1.841 \\
\hline & & & & & $\mathrm{T}$ & 0.36 \\
\hline & & & & & $G \times T$ & 2.954 \\
\hline \multirow[t]{3}{*}{$\mathrm{BMI}\left(\mathrm{kg} / \mathrm{m}^{2}\right)$} & $20.05 \pm 1.11$ & $19.54 \pm 1.23$ & $19.30 \pm 1.47$ & $19.70 \pm 1.41$ & G & 0.081 \\
\hline & & & & & $\mathrm{T}$ & 0.336 \\
\hline & & & & & $\mathrm{G} \times \mathrm{T}$ & $5.261^{*}$ \\
\hline \multirow[t]{3}{*}{ Body fat (\%) } & $22.07 \pm 1.23$ & $20.85 \pm 1.07$ & $22.40 \pm 2.84$ & $22.35 \pm 2.59$ & G & $13.673^{* *}$ \\
\hline & & & & & $\mathrm{T}$ & 1.19 \\
\hline & & & & & $\mathrm{G} \times \mathrm{T}$ & $11.922^{* *}$ \\
\hline
\end{tabular}

Values are presented as mean \pm standard deviation.

$\mathrm{SC}$, spinning cycle; GB, general bicycle; BMI, body mass index; G, group; T, time.

${ }^{*} P<0.05 .{ }^{* *} P<0.01 .{ }^{* *} P<0.001$.

Table 3. Changes in performance related physical fitness factors

\begin{tabular}{|c|c|c|c|c|c|c|}
\hline \multirow{2}{*}{ Variable } & \multicolumn{2}{|c|}{ SC group $(n=12)$} & \multicolumn{2}{|c|}{ GB group $(n=12)$} & \multirow{2}{*}{\multicolumn{2}{|c|}{ F-value }} \\
\hline & Pre & Post & Pre & Post & & \\
\hline \multirow[t]{3}{*}{ 1,200-m run (sec) } & $433.67 \pm 39.74$ & $411.83 \pm 28.01$ & $436.25 \pm 36.19$ & $422.58 \pm 29.14$ & G & $29.173^{* * *}$ \\
\hline & & & & & $\mathrm{T}$ & 0.25 \\
\hline & & & & & $\mathrm{G} \times \mathrm{T}$ & 1.544 \\
\hline \multirow[t]{3}{*}{ Sit-up (rep/30 sec) } & $32.75 \pm 4.33$ & $36.75 \pm 3.98$ & $32.5 \pm 4.46$ & $34.17 \pm 3.90$ & G & $90.829^{* * *}$ \\
\hline & & & & & $\mathrm{T}$ & 0.712 \\
\hline & & & & & $\mathrm{G} \times \mathrm{T}$ & $16.333^{* *}$ \\
\hline \multirow[t]{3}{*}{ Back strength $(\mathrm{kg})$} & $64.62 \pm 6.23$ & $69.83 \pm 5.03$ & $62.50 \pm 6.31$ & $64.50 \pm 5.62$ & G & $65.179 * * *$ \\
\hline & & & & & $\mathrm{T}$ & 2.549 \\
\hline & & & & & $\mathrm{G} \times \mathrm{T}$ & $12.912^{* *}$ \\
\hline \multirow[t]{3}{*}{ Sit and reach $(\mathrm{cm})$} & $17.48 \pm 1.49$ & $19.62 \pm 1.71$ & $17.71 \pm 2.20$ & $19.04 \pm 2.41$ & G & $75.932^{* * *}$ \\
\hline & & & & & $\mathrm{T}$ & 0.049 \\
\hline & & & & & $\mathrm{G} \times \mathrm{T}$ & 4.214 \\
\hline \multirow[t]{3}{*}{ Side step (rep/20 sec) } & $25.83 \pm 2.32$ & $28.67 \pm 2.35$ & $25.08 \pm 2.81$ & $27.00 \pm 2.76$ & G & $204.223^{* * *}$ \\
\hline & & & & & $\mathrm{T}$ & 1.357 \\
\hline & & & & & $\mathrm{G} \times \mathrm{T}$ & $7.606^{*}$ \\
\hline
\end{tabular}

Values are presented as mean \pm standard deviation.

$\mathrm{SC}$, spinning cycle; $\mathrm{GB}$, general bicycle; $\mathrm{G}$, group; $\mathrm{T}$, time.

${ }^{*} P<0.05$. ${ }^{* *} P<0.01$. ${ }^{* *} P<0.001$.

\section{RESULTS}

Table 2 shows the changes in body composition between spinning cycle and general bicycle groups following 16-week training. There were significant differences between groups (height: $F=$ 64.816, $P=0.001$; $\%$ body fat: $F=13.673, P=0.002$ ). Also there were significant differences in the group $\times$ time (BMI: $F=5.261$,
$P=0.002 ; \%$ body fat: $F=11.922, P=0.001)$.

Table 3 shows the changes in physical fitness between spinning cycle and general bicycle groups following 16-week training. There were significant differences between groups (1,200-m run: $F=29.173, P=0.000$; sit-up: $F=90.829, P=0.000$; back strength: $F=65.179, P=0.000$; sit and reach: $F=75.932, P=0.000$; and side-step: $F=204.223, P=0.000$ ). Also there were significant dif- 
Table 4. Changes in blood various

\begin{tabular}{|c|c|c|c|c|c|c|}
\hline \multirow{2}{*}{ Variable } & \multicolumn{2}{|c|}{ SC group ( $n=12$ ) } & \multicolumn{2}{|c|}{ GB group $(n=12)$} & \multirow{2}{*}{\multicolumn{2}{|c|}{ F-value }} \\
\hline & Pre & Post & Pre & Post & & \\
\hline \multirow[t]{3}{*}{$\mathrm{TC}(\mathrm{mg} / \mathrm{dL})$} & $163.16 \pm 11.46$ & $152.42 \pm 8.99$ & $165.66 \pm 14.18$ & $158.25 \pm 12.53$ & G & $125.483^{* * *}$ \\
\hline & & & & & $\mathrm{T}$ & 0.751 \\
\hline & & & & & $G \times T$ & 4.225 \\
\hline \multirow[t]{3}{*}{ LDL-C (mg/dL) } & $89.25 \pm 6.81$ & $80.33 \pm 5.19$ & $90.25 \pm 8.86$ & $82.75 \pm 7.35$ & G & $153.395^{* * *}$ \\
\hline & & & & & $\mathrm{T}$ & 0.358 \\
\hline & & & & & $\mathrm{G} \times \mathrm{T}$ & 1.142 \\
\hline \multirow[t]{3}{*}{ Glucose (mg/dL) } & $83.50 \pm 6.41$ & $77.42 \pm 6.76$ & $82.08 \pm 8.66$ & $81.17 \pm 5.81$ & G & $14.773^{* *}$ \\
\hline & & & & & $\mathrm{T}$ & 0.186 \\
\hline & & & & & $G \times T$ & $8.048^{*}$ \\
\hline \multirow[t]{3}{*}{$\mathrm{ROS}$ (pg/mL) } & $80.06 \pm 6.49$ & $86.83 \pm 5.88$ & $82.50 \pm 6.42$ & $86.94 \pm 7.07$ & G & $177.560^{* * *}$ \\
\hline & & & & & $\mathrm{T}$ & 0.238 \\
\hline & & & & & $G \times T$ & $7.707^{*}$ \\
\hline \multirow[t]{3}{*}{ MDA (pmol/mg) } & $0.151 \pm 0.014$ & $0.126 \pm 0.015$ & $0.145 \pm 0.016$ & $0.128 \pm 0.019$ & G & $45.794^{* * *}$ \\
\hline & & & & & $\mathrm{T}$ & 0.97 \\
\hline & & & & & $\mathrm{G} \times \mathrm{T}$ & 2.293 \\
\hline
\end{tabular}

Values are presented as mean \pm standard deviation.

SC, spinning cycle; GB, general bicycle; TC, cholesterol; LDL-C, low-density lipoprotein cholesterol; ROS, reactive oxygen species; MDA, malondialdehyde; G, group; T, time. ${ }^{*} P<0.05 .{ }^{* *} P<0.01 .{ }^{* * *} P<0.001$.

ferences in the group $\times$ time (sit-up: $F=16.333, P=0.001$; back strength: $F=12.912, P=0.002$; and side step: $F=7.606, P=0.011$ ).

Table 4 shows the changes in blood variables between spinning cycle and general bicycle groups following 16-week training. There were significant differences between groups (TC: $F=$ 125.483, $P=0.000$; LDL-C: $F=153.395, P=0.000$; glucose: $F=14.773, P=0.001$; ROS: $F=177.560, P=0.000$; and MDA: $F=45.794, P=0.000)$. Also there were significant differences in the group $\times$ time (glucose: $F=8.048, P=0.01$; ROS: $F=7.707$, $P=0.011)$.

\section{DISCUSSION}

Results showed that 16 weeks of regular aerobic exercises induced positive changes in body composition, physical fitness, and blood variables, which is remarkably greater in spinning exercise group as compared to general bicycle group. It corresponds to the findings that spinning exercise consumes more energy than bicycling at the same exercise intensity (THR, 40\%-65\%) as reported by Dandanell et al. (2017) that 16-week aerobic exercise in female middle school students reduced BMI and \% body fat, indicating that aerobic exercise is an effective tool to prevent obesity and reduce body fat. As results of regular aerobic exercise, cardiopulmonary endurance, muscular endurance and strength, flexibility and agility were improved, and regular exercise programs are import- ant for maintenance and care. It is reported that it helps to improve the physical fitness of girls, especially those who have low activity (Lee et al., 2017).

The effect of 16 weeks of aerobic exercise on blood lipids was improved and the antioxidant function was also positively changed in this study, which corresponds to the previous report (Devries et al., 2008) that the blood lipids decreased and the ROS and MDA showed positive changes through regular aerobic exercise.

As shown in this study, physical activity of female middle school students improved physique, physical fitness, blood lipid index, and antioxidant function. In addition, it was concluded that even with the same intensity of aerobic exercise, the more energy consuming modality such as spinning exercise are more beneficial for physical development and fitness.

\section{CONFLICTS OF INTEREST}

No potential conflict of interest relevant to this article was reported.

\section{ACKNOWLEDGMENTS}

This work was supported by the Daejeon Health Institiute of Thchnology Research Fund (No. 2016018). 


\section{REFERENCES}

American College of Sports Medicine. ACSM's health-related physical fitness assessment manual. Philadelphia (PA): Lippincott Williams \& Wilkins; 2013.

Battista RA, Foster C, Andrew J, Wright G, Lucia A, Porcari JP. Physiologic responses during indoor cycling. J Strength Cond Res 2008;22:12361241.

Caria MA, Tangianu F, Concu A, Crisafulli A, Mameli O. Quantification of spinning bike performance during a standard 50-minute class. J Sports Sci 2007;25:421-429.

Cattuzzo MT, Dos Santos Henrique R, Ré AH, de Oliveira IS, Melo BM, de Sousa Moura M, de Araújo RC, Stodden D. Motor competence and health related physical fitness in youth: a systematic review. J Sci Med Sport 2016;19:123-129.

Chaddock L, Pontifex MB, Hillman CH, Kramer AF. A review of the relation of aerobic fitness and physical activity to brain structure and function in children. J Int Neuropsychol Soc 2011;17:975-985.

Dandanell S, Elbe AM, Pfister G, Elsborg P, W Helge J. Relationship between volition, physical activity and weight loss maintenance: study rationale, design, methods and baseline characteristics. Scand J Public Health 2017;45:299-304.

Devries MC, Hamadeh MJ, Glover AW, Raha S, Samjoo IA, Tarnopolsky MA. Endurance training without weight loss lowers systemic, but not muscle, oxidative stress with no effect on inflammation in lean and obese women. Free Radic Biol Med 2008;45:503-511.

Greydanus DE, Omar HA. Adolescence and human sexuality. In: Merrick J, Tenenbaum A, Omar HA, editors. Adolescence and sexuality: international perspectives. Hauppauge (NY): Nova Science Publishers; 2014. p. 9-61.

Hazelhurst LT, Claassen N. Gender differences in the sweat response during spinning exercise. J Strength Cond Res 2006;20:723-724.
Kang J, Chaloupka EC, Mastrangelo MA, Hoffman JR, Ratamess NA, $\mathrm{O}^{\prime}$ Connor E. Metabolic and perceptual responses during Spinning cycle exercise. Med Sci Sports Exerc 2005;37:853-859.

Lee EY, Spence JC, Song YK, Jeon JY. A systematic review of the correlates of Korean girls' physical activity: an ecological perspective. Health Soc Sci 2015;40:5-28.

Lee KJ, Shin YA, Lee KY, Jun TW, Song W. Aerobic exercise training-induced decrease in plasma visfatin and insulin resistance in obese female adolescents. Int J Sport Nutr Exerc Metab 2010;20:275-281.

Lee KS, Lee JK, Yeun YR. Effects of a 10-day intensive health promotion program combining diet and physical activity on body composition, physical fitness, and blood factors of young adults: a randomized pilot study. Med Sci Monit 2017;23:1759-1767.

Lee S, Bacha F, Hannon T, Kuk JL, Boesch C, Arslanian S. Effects of aerobic versus resistance exercise without caloric restriction on abdominal fat, intrahepatic lipid, and insulin sensitivity in obese adolescent boys: a randomized, controlled trial. Diabetes 2012;61:2787-2795.

López-Miñarro PA, Rodríguez JM. Heart rate and overall ratings of perceived exertion during Spinning ${ }^{\circledR}$ cycle indoor session in novice adults. Sci Sports 2010;25:238-244.

Petersen PE, Ueda H. Oral health in ageing societies: integration of oral health and general health: report of a meeting convened at the WHO Centre for Health Development in Kobe, Japan, 1-3 June 2005. Geneva: World Health Organization; 2008.

Rhyu HS, Cho SY. The effect of weight loss by ketogenic diet on the body composition, performance-related physical fitness factors and cytokines of Taekwondo athletes. J Exerc Rehabil 2014;10:326-331.

Strong WB, Malina RM, Blimkie CJ, Daniels SR, Dishman RK, Gutin B, Hergenroeder AC, Must A, Nixon PA, Pivarnik JM, Rowland T, Trost $\mathrm{S}$, Trudeau F. Evidence based physical activity for school-age youth. J Pediatr 2005;146:732-737. 